\title{
Etiologic Heterogeneity of the Psychoses: Is There a Dopamine Psychosis?
}

David L. Garver, M.D., Joel L. Steinberg, M.D., Barbara E. McDermott, Ph.D., Jeffrey K. Yao, Ph.D., Jane E. Ramberg, M.S., Steve Lewis, M.D., and Steven J. Kingsbury, M.D., Ph.D.

The distribution of drug-free plasma homovanillic acid ( $p H V A$ ) concentrations was studied in a sample of psychotic patients, some of whom were selected for good prognostic features. Baseline $p H V A$ was bimodally distributed, suggesting two different patient populations. The high-pHVA patients showed periods of better functioning and/or fewer symptoms 5 years before admission $(p<.05)$ and had a more rapid $(p<.05)$ and complete $(p<.001)$ subacute neuroleptic response than lower-pHVA psychotics. High-pHVA psychotics did not differ

KEY WORDS: Schizophrenia; Psychosis; Dopamine; Homovanillic acid; Heterogeneity; Neuroleptic

Despite the posited association of dopamine with psychosis since the 1960s, there has been little support for such a direct linkage in the recent psychiatric literature. Anden et al. (1970) first suggested that the newly discovered antipsychotic drugs had but one characteristic in common: they blocked access of dopamine to dopamine receptors. Seeman et al. (1975) and Creese et al. (1976) found that the affinity of various drugs for central dopamine ${ }_{2}\left(D_{2}\right)$ receptors is inversely related to the dose at which conventional antipsychotics are administered.

From the Departments of Psychiatry, Southwestern Medical Center of the Lniversity of Texas (DLG, JLS, SJK), and Dallas Veterans Affairs Medical Center (DLG, JLS, JER, SJK), Dallas, TX; Tulane University (BEM), New Orleans, LA; Pittsburgh Veterans Affairs Medical Center (JKY), Pittsburgh, PA; and Tucson Veterans Affairs Medical Center (SL), Tucson, AZ.

Address correspondence to: David L. Garver, M.D., Dallas VAMC (116A), 4500 S. Lancaster Road, Dallas, TX 75216.

Received February 8, 1996; revised June 6, 1996; accepted July 25, 1996. in other aspects of demographics or clinical presentation from lower-pHVA psychotics. Compared to the general population, there were more psychotics in the families of high-pHVA patients $(p<.005)$. Rapid antipsychotic response by high-pHVA psychotics is consistent with blockade of the effects of excess synaptic dopamine at $D_{2}$ receptors for these patients. Results are discussed in the context of the syndromic heterogeneity of the psychoses. (C) 1997 American College of Neuropsychopharmacology

[Neuropsychopharmacology 16:191-201, 1997]

Others observed that dopamine-releasing agents, such as amphetamine, induced or worsened existing psychoses in some (Janowsky and Davis 1976; Angrist and Gershon 1977), but not all (Van Kammen et al. 1982) psychotic patients.

Since the 1970s, only a few fragments of additional information have further supported this dopamine hypothesis of psychosis. An excess of $\mathrm{D}_{2}$ (Seeman et al. 1984; Wong et al. 1986) and $D_{4}$ (Seeman et al. 1993) dopamine receptors have been reported in some areas of the schizophrenic brain. Reynolds (1983) reported a localized excess of dopamine in the left amygdala. However, evidence for a more widespread excess of dopamine itself or for excess dopamine turnover is lacking. Most (Davidson and Davis 1988; Baker et al. 1990; Markianos et al. 1992; Wei et al. 1992; Steinberg et al. 1993; Koreen et al. 1994), but not all (Pickar et al. 1984; Doran et al. 1985) investigators have found that plasma concentrations of homovanillic acid (pHVA), the primary metabolite of brain dopamine, are normal or slightly below normal in most psychotics. Furthermore, the existence of delayed antipsychotic effects of neuroleptic drugs in most psychotic patients is hardly consistent with a simple hypothe- 
sis of excess synaptic dopamine or of excess dopamine receptors in psychosis. For most patients, the disappearance/attenuation of hallucinations and disordered thinking requires several weeks of continuous antipsychotic drug treatment following $\mathrm{D}_{2}$ blockade (Baldessarini 1985). Response would be expected within the first few days of treatment (following effective dopamine receptor blockade) if psychosis was simply the result of either excess synaptic dopamine or an excess of $\mathrm{D}_{2}$ receptors.

However, a poorly defined subgroup of psychotic patients has been repeatedly documented to have an early antipsychotic response following the initiation of receptor-blocking doses of antipsychotics. Such an early response to an antipsychotic has been documented by several investigators to occur by day 10 of drug treatment (Reschke 1973; Donlon and Tupin 1974; Anderson et al. 1976; Mason and Granacher 1976; Lerner et al. 1979; Neborsky et al. 1981; Keck et al. 1989; Glovinsky et al. 1992). We have previously described dramatic antipsychotic effects in a subgroup of patients by day 4 of neuroleptic drug administration (Garver et al. 1988). Such early antipsychotic responders have been reported to have higher pHVA than found in most other psychotic patients (Bowers et al. 1984, 1986; Van Putten et al. 1989; Koreen et al. 1994).

pHVA, found in such excess in early responders, is a product of the breakdown of dopamine synthesized in both dopamine and norepinephrine (NE) neurons. Changes in presynaptic brain dopamine activity appear to be well-correlated with changes in pHVA (Amin et al. 1992). However, studies with debrisoquin, an inhibitor of the peripheral metabolism of dopamine to HVA, have suggested that about only $30 \%$ of pHVA comes from the central nervous system (Kopin et al. 1988). Thus, despite the high correlation between brain dopamine activity and pHVA, $70 \%$ of pHVA appears to be a metabolic by-product of NE synthesis in peripheral sympathetic neurons.

In response to observations that higher drug-free pHVA is associated with an early antipsychotic response following neuroleptic initiation, we have entertained the possibility that such early antipsychotic response (versus slower response in lower-pHVA patients) might signal fundamentally different mechanisms of both pathophysiology and drug action within the highversus lower-pHVA groups. Early response is consistent with a simple interruption of excess dopamine neurotransmission facilitated directly by neuroleptic blockade of dopamine receptors. The delayed antipsychotic response found in most psychotic patients (who also achieve receptor blockade within the first few days following drug initiation), appears to involve a more complex and prolonged cascade of events that are nonetheless triggered by $\mathrm{D}_{2}$ blockade. If there are such pharmacodynamic differences in the mechanisms of action of neuroleptic drugs in two subgroups of psychotic patients, such differences might aid in separating two (or more) pathophysiologically distinct disorders from one another (Garver et al. 1988).

The initial goal of this investigation was to replicate the findings of other investigators that psychotic patients with drug-free high pHVA respond more rapidly than psychotics with lower pHVA. We also wanted to confirm that such difference in speed of response cannot be accounted for by differences in neuroleptic blood levels, age, or duration of illness and to determine that differences in pHVA are not the consequence of variations in NE metabolism.

Such confirmations allowed us then to characterize and separate a high-pHVA group of psychotic patients from lower-pHVA psychotics. We examined the parameters widely used to define and delineate a disease that is etiologically and mechanistically distinct from other conditions and yet may bear some superficial resemblance. Of particular interest are differences in presenting symptoms, course of illness, laboratory findings, and response to therapeutic intervention. Of further interest is the question of whether high-pHVA psychosis is a familial disorder. If high-pHVA psychosis is familial, linkage studies would be of future interest and the concept of genetic heterogeneity of the psychoses would be strengthened.

We hypothesized that we would not be able to distinguish high- from lower-pHVA psychotics by neuroleptic drug levels during treatment, age, duration of illness, plasma NE metabolites (indicating central and peripheral adrenergic activity), or presenting symptoms (as these would have been used previously to characterize the subtype). We predicted that the high-pHVA psychotics would have a dissimilar mode of pHVA distribution, illness course (higher functioning between episodes), and antipsychotic response (early and more complete response following neuroleptic initiation). Finally, we hypothesized that high-pHVA psychosis would be a familial disorder (evidenced by a greater risk of psychosis in family members than the general population).

\section{SUBJECTS AND METHODS}

Thirty-two recently admitted psychotic patients [17 DMS-III schizophrenics, 4 schizophreniform disorders, 6 manic, and 2 depressed psychotic mood-incongruent affective disorders, 2 mood-congruent psychotic manics, and 1 schizoaffective disorder (bipolar type)] were admitted to the Psychobiology Treatment Unit from ambulatory status during initiation/exacerbation of psychotic illness. Selection of patients for admission was purposefully skewed toward the inclusion of some patients who had had relatively good vocational and social functioning in the 5 years prior to admission. We aimed to study essentially equal numbers of psychotic patients with good and poorer prognoses. Six control subjects were admit- 
ted to the adjacent General Clinical Research Center for baseline evaluation and biological studies. Each subject had consented to a 10-day drug-free period (except for up to $8 \mathrm{mg}$ /day of lorazepam in psychotic patients, if needed for behavioral control). Eighty-one percent of these patients had been drug-free for $>90$ days prior to pHVA collection. The remaining patients were drug-free for 10 to 39 days prior to the drawing of samples for pHVA. For data classification and collection we used the Schedule of Affective Disorders and Schizophrenia [SADS (Endicott and Spitzer 1978)], its summary scores (Endicott 1978), the Diagnostic and Statistical Manual III [DSM-III (American Psychiatric Association 1980)], and the Brief Psychiatric Rating Scale [BPRS (Overall and Gorham 1962)] and its subscales (Hollister et al. 1967). Best period of work adjustment, social conduct, pleasurable social relations, and least overall symptomatology during the preceding 5 years were estimated from the sum of the two most relevant items of the SADS [\#1242 and \#1245 (Endicott 1978)]. Following a 12-hour fast, a series of drug-free biological studies were undertaken, including a 7:30 A.M baseline plasma sample for pHVA and pMHPG. Subjects had not received lorazepam for 48 hours prior to collection of this sample. Plasma for haloperidol levels was also taken at 7:30 A.M. on days 7 and 14 of haloperidol treatment.

The plasmas were immediately frozen and stored at $-70^{\circ} \mathrm{C}$ until shipment on dry ice to Highland Avenue Veterans Affairs Medical Center in Pittsburgh. The pHVA and pMHPG assays were modifications (Chang et al. 1983) of the Scheinin et al. (1983) procedure for simultaneous assessment of HVA and MHPG. The pHVA assay had an intraassay coefficient of variation (CV) of $2.2 \%$ at 50 to $150 \mathrm{pmol} / \mathrm{ml}$; the intraassay $\mathrm{CV}$ for $\mathrm{pMHPG}$ was $6.62 \%$ at $60 \mathrm{nmol} / \mathrm{ml}$. Plasma samples taken at days 7 and 14 during haloperidol treatment were sent on dry ice to the Nathan Kline Institute, Orangeburg, New York. The haloperidol assay, using gas-liquid chromatography with a nitrogen-phosphorous detector operated in the nitrogen mode (Bianchetti and Morselli 1978) had a sensitivity of $1 \mathrm{ng} / \mathrm{ml}$ and CVs of $6 \%$ at 2.5 $\mathrm{ng} / \mathrm{ml}$ and $3.9 \%$ to $4.6 \%$ over the range of 5 to $30 \mathrm{ng} / \mathrm{ml}$.

Seventeen of the original 32 patients further consented to a systematic treatment trial with haloperidol at doses adjusted between 4 and $30 \mathrm{mg} /$ day for periods of 2 to 6 weeks. Studies on this same sample showed no advantage of higher doses over $4 \mathrm{mg}$ haloperidol/day (Stone et al. 1995). BPRS psychosis ratings were performed three times weekly during the first 2 weeks of the haloperidol trial and weekly thereafter until the time of discharge in order to monitor the time course of haloperidol's antipsychotic effects. Psychosis (BPRS "S") scores were the sum of three BPRS items: conceptual disorganization, hallucinatory behavior, and unusual thought content (Hollister et al. 1967). For each patient, these scores were plotted on a 28-day timeline; "timepoint" scores were interpolated for days $1,4,7,10,14,21$, or 28 of haloperidol treatment, if necessary (to compensate for intervening weekends or holidays when patients were not rated). "Endpoint" ratings (discharge ratings carried through to day 28) were used for patients who were released from the hospital before completing 28 days of haloperidol treatment. Maximum subacute improvement was the greatest reduction of BPRS " $\mathrm{S}$ " scores during the treatment period (generally at day 28 , the last timepoint). The interrater intraclass correlation coefficient (Winer et al. 1991) for two raters of the BPRS was 0.96.

A family interviewer, blind to information concerning the presence or absence of psychiatric disturbance in patients' pedigrees, conducted (in person or by telephone) SADS interviews on multiple first-degree family members (parents, siblings, or offspring) of 16 of the original 32 patients. The evaluations and diagnoses were made by the interviewer, who was also blind to the proband's previous functional history, current diagnosis, biological data, or drug responsiveness. When it was not possible to interview a relative directly, the family history method was used to assign a diagnosis only when the details supporting the diagnosis could be confirmed unambiguously by at least two relatives. Interrater reliability (unweighted kappa) for seven diagnostic categories was 0.81 for 20 relatives interviewed directly by two raters (Sautter et al. 1986).

Statistical analyses were performed with SYSTAT (1992) and SigmaStat (1992-1994) software. The normality of the distribution of pHVA was assessed with the Kolmogorov-Smirnov one-sample test using a standard normal distribution (Lilliefors test). K-means splitting methods (cluster analyses) were used to estimate the means \pm SD and range of the bimodal distribution. Between-group comparisons of data with normal distributions were assessed by Student's $t$-tests computed for equal or unequal variance, as required. Comparisons of between-group data without a normal distribution or with unequal variance were analyzed by the Mann Whitney Rank Sum Test. For categorical measures, Pearson's $\chi^{2}$ was used. Assuming a 10 in 1,000 lifetime risk for schizophrenia in the general population, first-degree relatives of the psychotic probands were assessed for an excess of DSM-III schizophrenia by Differences of Sample Proportions (with Yates correction). Bonferroni corrections were used for multiple tests.

Relationships between both the baseline BPRS " $\mathrm{S}$ " scores and the global assessment score (GAS) from SADS were examined with respect to baseline pHVA with Pearson's correlations $\left(r_{p}\right)$. Differences between high- and lower-pHVA patients in BPRS " $\mathrm{S}$ " scores over time were assessed by repeated-measures analysis of variance (ANOVA), with contrasts (comparing each timepoint score with the baseline score using the C-matrix). Maximum subacute improvement (during hospitalization) in percent change from baseline was docu- 
Table 1. Demographic Data for All Patients

\begin{tabular}{lc}
\hline DSM-III Diagnosis & \\
$\quad$ Schizophrenia & 17 \\
Schizophreniform disorder & 4 \\
$\quad$ Psychotic affective disorders & 11 \\
Sex (M/F) & $14 / 18$ \\
Current age (mean years \pm SD) & $29.5 \pm 9.5$ \\
Age at onset (mean years \pm SD) & $23.5 \pm 7.2$ \\
Duration of present psychotic episode & \\
$\quad$ (mean weeks \pm SD) & $95.6 \pm 177.6$ \\
Duration of illness (since first episode) & \\
$\quad$ (mean years \pm SD) & $5.9 \pm 5.1$ \\
Baseline BPRS “S" (mean score \pm SD) & $9.2 \pm 2.7$ \\
\hline
\end{tabular}

mented for patients and for patient groups. The percent of maximum subacute improvement of the BPRS " $\mathrm{S}$ " scores at each timepoint was calculated as follows: $[($ Baseline $\times$ Timepoint score $) /($ Baseline $\times$ Most improved score) $] \times 100$.

\section{RESULTS}

\section{Patient Demographics}

Table 1 presents demographic data on 32 psychotic patients who agreed to participate in drug-free, baseline studies. Because we anticipated encountering a preponderance of chronic psychotics, we sought to balance our cohort with patients who had more favorable prognoses. In the final sample $53 \%$ of the subjects were found to have DSM-III schizophrenia, 13\% schizophreniform disorder, and $34 \%$ psychotic affective disorders.

\section{Bimodal Distribution of pHVA}

The distribution of pHVA in drug-free psychotic patients is displayed in Figure 1 and Table 2. Four "outliers" (pHVA values $>2$ SD higher than the mean of displayed pHVA values) are excluded from the analyses. Separate analyses that included these outliers, not reported herein, did not substantially change subsequent analyses. The distribution of pHVA differed significantly from normal (Komogorov-Smirnov one-sample test using standard normal distribution: Lilliefors maxdif $=0.162$, 2 -tailed $p=.033$ ). The pHVA distribution fit a two-cluster model (K-Means Splitting: $F=134.4 \mathrm{df}=1,30, p<$ $.001)$. The lower-pHVA cluster $(n=17)$ had a mean \pm $\mathrm{SD}$ of $53.6 \pm 12.5 \mathrm{pmol} \mathrm{pHVA} / \mathrm{ml}$ (range 23.6 to 75.0 ); the high-pHVA cluster $(n=15)$ had a pHVA of $115.1 \pm$ $16.4 \mathrm{pmol} / \mathrm{ml}$ (range 86.4 to 148.1 ). A small group of 6 healthy controls (age $24 \pm 2$ years) with bloods collected under identical inpatient conditions showed a pHVA of $83.9 \pm 13.4$ (range 66.2 to 98.8 ) $\mathrm{pmol} / \mathrm{ml}$.

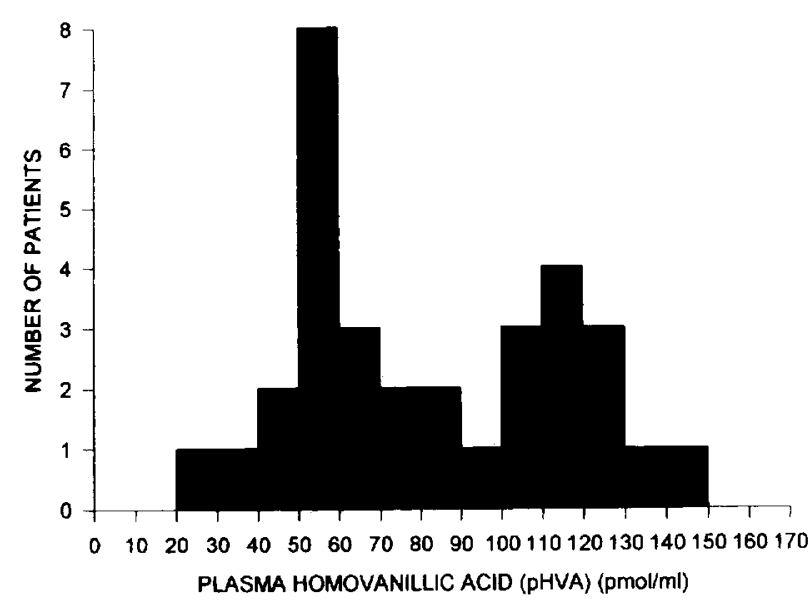

Figure 1. Frequency histogram of the distribution of pHVA in the psychotic patients.

\section{Plasma MHPG and HVA}

There were no significant differences in the distribution of pMHPG across the two pHVA distributions. LowerpHVA patients had a pMHPG of $38.2 \pm 11.9 \mathrm{pmol} / \mathrm{ml}$; high-pHVA patients, $38.5 \pm 20.4$ (Mann-Whitney $T=$ $224.5, p=.395)$. Consequently, the ratio of pHVA to pMHPG was significantly higher in the high-pHVA patients than in the lower-pHVA group ( $3.9 \pm 1.7$ versus $1.7 \pm 1.1$, respectively; Mann-Whitney $T=343.0 ; p<$ .001). pHVA and pMHPG were not correlated $\left(r_{p}=.018\right.$, $p=.92)$.

\section{Characteristics of Psychoses with Lower versus High pHVA}

As shown in Table 3, an analysis of patient data with respect to the two pHVA distributions showed that over the preceding 5 years high-pHVA psychotics had periods during which they experienced minimal or no symptoms, closeness to two or more special friends, and/or no more than a slight impairment of functioning (sum of SADS \#1242 and \#1245 [Endicott 1978]: $4.9 \pm 3.2$ ). In contrast, during the preceding 5 years lower-pHVA psychotics had at best mild to moderate symptoms, a single or no special close friend, and/or some difficulty in several areas of functioning $(7.1 \pm 2.5)$ (Student's $t=$ $2.11, \mathrm{df}=26, p=.0449$ ). There was no significant between-group difference with respect to age of onset, duration of illness, current age, DSM-III diagnosis, or baseline BPRS " $\mathrm{S}$ " psychosis scores. There was a trend (chi square $=3.35 ; p=0.67$ ) in favor of a greater proportion of females in the high-pHVA group. Consistent with the findings for the entire group of psychotics, limiting the data set to DSM-III schizophrenics $(n=15)$, high-pHVA schizophrenics showed a trend (Mann- 
Table 2. Psychotic Patients in High and Lower pHVA Groups

\begin{tabular}{|c|c|c|c|c|c|c|c|c|c|c|c|}
\hline & $\begin{array}{c}\text { DSM-III } \\
\text { Diagnosis }\end{array}$ & Sex & Age & $\begin{array}{l}\text { Age at } \\
\text { Onset }\end{array}$ & $\begin{array}{c}\text { Duration } \\
\text { of Illness } \\
\text { (Years) }\end{array}$ & $\begin{array}{l}\text { Duration } \\
\text { of Current } \\
\text { Episode } \\
\text { (Weeks) }\end{array}$ & $\begin{array}{l}\text { Gas } \\
\text { Score } \\
\text { Past } \\
\text { Week }\end{array}$ & $\begin{array}{l}\text { Baseline } \\
\text { BPRS } \\
\text { "S" Score }\end{array}$ & $\begin{array}{l}\text { \% Maximum } \\
\text { Improvement } \\
\text { (BPRS “S" } \\
\text { Scores), }(N=17)^{a}\end{array}$ & $\begin{array}{c}\text { pHVA } \\
(\mathrm{nmol} / \mathrm{ml})\end{array}$ & $\begin{array}{c}\text { pMHPG } \\
(\mathrm{nmol} / \mathrm{ml})\end{array}$ \\
\hline \multicolumn{12}{|c|}{$\begin{array}{l}\text { Lower-pHVA } \\
\text { group }\end{array}$} \\
\hline 1 & $S$ & $\mathrm{~F}$ & 32 & 28 & 4 & 104 & 63 & 13 & * & 23.6 & 26.6 \\
\hline 2 & Dmip & $\mathrm{M}$ & 34 & 32 & 2 & 8 & 21 & 10 & * & 32.9 & 42.5 \\
\hline 3 & $\mathrm{~S}$ & $\mathrm{~F}$ & 26 & 19 & 7 & 3 & 34 & 9 & * & 40.4 & 30.4 \\
\hline 4 & $\mathrm{~S}$ & $\mathrm{M}$ & 21 & 17 & 4 & 10 & 30 & 10 & 30.0 & 47.0 & 42.9 \\
\hline 5 & Mmip & $\mathrm{F}$ & 36 & 31 & 5 & 4 & 36 & 9 & * & 50.1 & 53.3 \\
\hline 6 & S & $\mathrm{M}$ & 24 & 17 & 7 & 104 & 35 & No data & No data & 50.7 & 40.8 \\
\hline 7 & $\mathrm{~S}$ & M & 26 & 20 & 6 & 12 & 12 & 5 & 40.0 & 52.7 & 33.0 \\
\hline 8 & $S$ & $\mathrm{M}$ & 20 & 10 & 10 & 104 & 7 & 6 & 16.7 & 53.6 & 33.8 \\
\hline 9 & $S$ & $\mathrm{M}$ & 35 & 29 & 6 & 300 & 54 & 10 & $*$ & 54.1 & 9.7 \\
\hline 10 & SF & $\mathrm{F}$ & 22 & 22 & 0.04 & 2 & 24 & 10 & 70.0 & 56.2 & 32.6 \\
\hline 11 & $\mathrm{~S}$ & $\mathrm{M}$ & 44 & 33 & 11 & 26 & 33 & 11 & 45.5 & 56.5 & 41.3 \\
\hline 12 & M & $\mathrm{F}$ & 39 & 39 & 0.33 & 1 & No data & 9 & $*$ & 56.8 & 46.4 \\
\hline 13 & $S$ & $\mathbf{M}$ & 34 & 26 & 8 & 24 & 23 & 10 & 50.0 & 61.2 & 70.3 \\
\hline 14 & $S$ & $\mathrm{M}$ & 32 & 27 & 5 & 260 & 27 & 11 & 63.6 & 61.9 & 36.2 \\
\hline 15 & $\mathrm{SF}$ & $\mathrm{F}$ & 20 & 20 & 0.04 & 2 & 21 & 12 & 50.0 & 66.1 & 52 \\
\hline 16 & $S$ & $\mathrm{~F}$ & 26 & 22 & 4 & 208 & No data & 17 & 58.8 & 72.1 & 24.1 \\
\hline 17 & Mmip & M & 44 & 41 & 3 & 163 & 25 & 4 & $*$ & 75.0 & 40.8 \\
\hline \multicolumn{12}{|c|}{$\begin{array}{l}\text { High-pHVA } \\
\text { group }\end{array}$} \\
\hline 1 & Mmip & M & 36 & 29 & 7 & 6 & 41 & 8 & * & 86.4 & 52 \\
\hline 2 & SF & $\mathrm{F}$ & 59 & 32 & 22 & 6 & 31 & 10 & 70.0 & 89.9 & 36.8 \\
\hline 3 & $\mathrm{~S}$ & $\mathrm{M}$ & 22 & 20 & 2 & 75 & 43 & 10 & * & 95 & 16.8 \\
\hline 4 & M & $\mathrm{F}$ & 26 & 18 & 8 & 3 & 38 & 8 & * & 106 & 26.6 \\
\hline 5 & S & $\mathrm{F}$ & 21 & 21 & 0.75 & 36 & 35 & 10 & 90.0 & 106.1 & 26.3 \\
\hline 6 & S & $\mathrm{F}$ & 23 & 14 & 9 & 312 & No data & 10 & 90.0 & 107.5 & 15.6 \\
\hline 7 & $\mathrm{SAm} / \mathrm{d}$ & $\mathrm{F}$ & 22 & 17 & 5 & 6 & 36 & 5 & * & 115.6 & 18 \\
\hline 8 & Mmip & $\mathrm{F}$ & 39 & 31 & 8 & 2 & 46 & 5 & $*$ & 118.3 & 84 \\
\hline 9 & $\mathrm{SF}$ & $\mathrm{M}$ & 19 & 18 & 1 & 7 & 37 & 9 & 77.8 & 118.5 & 94.5 \\
\hline 10 & Mmip & $\mathrm{F}$ & 36 & 21 & 15 & 1 & No data & 4 & 50.0 & 119.2 & 32.4 \\
\hline 11 & $S$ & $\mathrm{~F}$ & 40 & 23 & 17 & 880 & 30 & 14 & $*$ & 124.6 & 32.8 \\
\hline 12 & Mmip & $\mathrm{M}$ & 20 & 20 & 0.33 & 17 & 38 & 13 & * & 125.8 & 23.6 \\
\hline 13 & Dmip & $\mathrm{F}$ & 21 & 20 & 2 & 6 & 32 & 11 & 81.8 & 128.6 & 32.2 \\
\hline 14 & S & $F$ & 19 & 16 & 3 & 7 & 39 & 13 & 84.6 & 136.3 & 31.4 \\
\hline 15 & $\mathrm{~S}$ & $\mathrm{~F}$ & 27 & 20 & 7 & 360 & 25 & 10 & 70.0 & 148.1 & 36.7 \\
\hline
\end{tabular}

Abbreviations: S, schizophrenia; Dmip, psychotic mood-incongruent affective disorder (depressed); Mmip, psychotic mood-incongruent affective disorder (manic); SF, schizophreniform disorder; M, psychotic mood-congruent manic, SAm/d, schizoaffective disorder, bipolar type.

"Haloperidol-treated patients.

* No haloperidol trial.

Whitney $T=25.0, p<.08$ ) toward periods of higher premorbid functioning in the past five years than lower pHVA schizophrenics.

Seventeen symptom clusters derived from SADS Summary Scores (Endicott 1978), available for 29 of the 32 patients across the two pHVA distributions, were also examined. The only difference between the highand lower-pHVA groups was in the Global Assessment Score (GAS) of the past week (Mann-Whitney $T=$ 239.0, $p=.02)$, which was eliminated when a Bonfer- roni correction was applied $(p=.34)$. No differences were found when the analysis was limited to the 15 DSM-III schizophrenics in both groups.

\section{Symptoms and pHVA Distributions}

In the total patient cohort, pHVA was not correlated with the baseline BPRS " $S$ " scores $\left(r_{p}=.02, p=.91\right)$. pHVA was poorly correlated with BPRS " $S$ " scores in the high group $\left(r_{p}=.419, p=.155\right)$. In the lower-pHVA group, 
Table 3. Demographic Data in Lower- versus High-pHVA Groups

\begin{tabular}{|c|c|c|}
\hline & \multicolumn{2}{|c|}{ pHVA Group } \\
\hline & $\begin{array}{l}\text { Lower } \\
(N=17)\end{array}$ & $\begin{array}{l}\text { High } \\
(N=15)\end{array}$ \\
\hline \multicolumn{3}{|l|}{ Diagnosis } \\
\hline Schizophrenia & 11 & 6 \\
\hline Schizophreniform disorder & 2 & 2 \\
\hline Psychotic affective disorders & 4 & 7 \\
\hline $\operatorname{Sex}(\mathrm{M} / \mathrm{F})$ & $10 / 7$ & $4 / 11$ \\
\hline Current age (mean years $\pm \mathrm{SD}$ ) & $30.3 \pm 7.9$ & $28.7 \pm 11.3$ \\
\hline Age at onset (mean years $\pm S D$ ) & $25.5 \pm 8.2$ & $21.3 \pm 5.3$ \\
\hline $\begin{array}{l}\text { Best vocational and social functioning in last } 5 \text { years } \\
\text { (mean score } \pm \mathrm{SD})\end{array}$ & $7.1 \pm 2.5$ & $4.9 \pm 3.2^{\prime \prime}$ \\
\hline Duration of illness (mean years $\pm \mathrm{SD}$ ) & $4.8 \pm 3.2$ & $7.1 \pm 6.5$ \\
\hline Duration of present psychotic episode (mean weeks $=\mathrm{SD}$ ) & $78.5 \pm 98.9$ & $114.9 \pm 240.6$ \\
\hline Baseline BPRS "S" (mean score $\pm \mathrm{SD}$ ) & $9.1 \pm 2.4$ & $9.4 \pm 3.1$ \\
\hline
\end{tabular}

"Better vocational and social functioning score in high-pHVA group.

(Student's $t=2.11, \mathrm{df}=2.6, \mu=.0449)$.

there was a nonsignificant trend for pHVA to be negatively correlated with BPRS "S" scores $\left(r_{p}=.44, p=.09\right)$.

\section{Antipsychotic Effects of Haloperidol and pHVA Distributions}

Seventeen of the 32 patients described above underwent a systematic treatment trial with haloperidol at doses adjusted to between 4 and $30 \mathrm{mg} /$ day for 2 to 6 weeks. Patients were discharged upon request, typically when positive psychotic symptoms had diminished sufficiently so as not to grossly interfere with daily activities. Patients with lower pHVA $(<80 \mathrm{pmol} / \mathrm{ml}),(n=$ 9) achieved $50.5 \% \pm 12.2 \%$ reduction of baseline BPRS "S" scores prior to discharge; patients with high pHVA $(>80 \mathrm{pmol} / \mathrm{ml})(n=8)$ achieved $76.8 \% \pm 13.3 \%$ reduction prior to their discharge (Student's $t$-test: $t=4.24 ; \mathrm{df}=$ $15 ; p<.001$ ). Similarly, repeated-measures ANOVA of BPRS S" scores followed by contrasts during systematic haloperidol trials revealed a trend toward a better response in the high-pHVA group by day $7(F=3.738, \mathrm{df}=$ $1,15, p=.072)$ and a significantly superior response by day $10(F=5.699, \mathrm{df}=1,15, p=.031)$ (Figure 2).

Percent change scores revealed a trend by day 4 ( $F=$ 3.326, $\mathrm{df}=1,15, p=.088$ ) and a significant difference in response favoring the high-pHVA group by day $7(F=$ $6.643, \mathrm{df}=1,15, p=.021)$ and at all subsequent timepoints. Percent of maximum subacute improvement scores further indicate a trend toward earlier response in the high-pHVA group by day $7(F=3.643, \mathrm{df}=1,15 ; p=.076)$ and a significantly earlier response at day $10(F=4.649$, $\mathrm{df}=1,15, p=.048$ ).

The 18 patients who underwent the haloperidol trial had a preponderance of females in the high-pHVA group $\left(\chi^{2}=5.951, p=.015\right)$. Baseline pHVA was positively correlated with the rapidity of response (beginning at day 7 of treatment) both within and across genders. The pHVA of male psychotics $(n=7)$ positively correlated with the percent improvement of the BPRS " $\mathrm{S}$ " score by day 7 of treatment $\left(r_{p}=.77, p=.04\right)$. A similar trend was found within females $(\mathrm{n}=10)$ by day 7 of treatment $\left(r_{p}=.55, p=.10\right)$, with significance by day $10\left(r_{p}=.68, p=\right.$

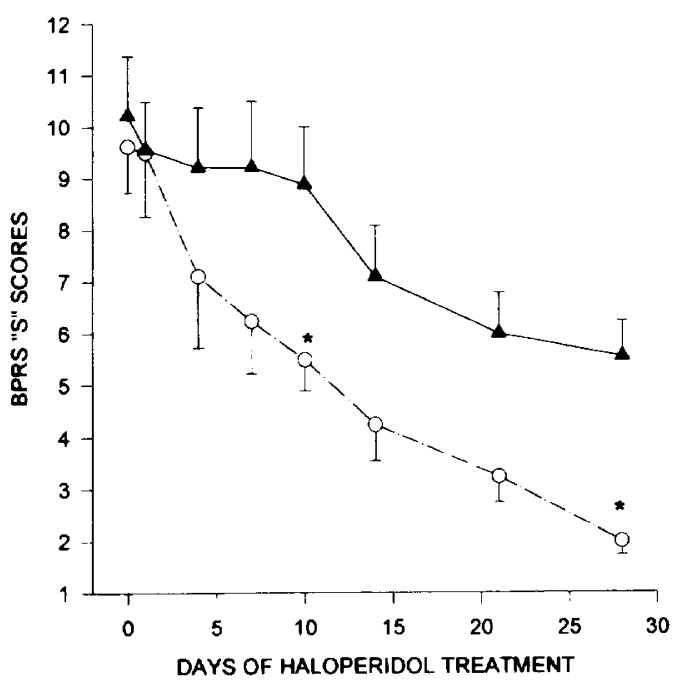

Figure 2. Mean antipsychotic response (last timepoint carried forward) of high- (circles) and lower- (triangles) pHVA groups during treatment with haloperidol. Symptoms were monitored with BPRS "S" scores. Vertical lines extending from each data point represent the SE. *Repeated-measures ANOVA followed by contrasts show significantly superior response in the highpHVA group by day $10(\mathrm{~F}=5.699 ; \mathrm{df}=1,15 ; p=.031)$. 
.03). Across genders $(n=17)$, baseline pHVA was correlated with percent improvement at day $7\left(r_{p}=.49, p=\right.$ $.05)$ and at day $10\left(r_{p}=.66, p=.005\right)$. Dichotomizing females by high and lower baseline pHVA, a better response $(>50 \%)$ was found by day 10 in the high-pHVA group $\left(\chi^{2}=4.29, \mathrm{df}=1, p=.04\right)$. A similar trend $\left(\chi^{2}=\right.$ $2.92, \mathrm{df}=1, p=.09$ ) was found within males by day 7 . Across genders, there was a trend toward better response in the high-pHVA group at day $7\left(\chi^{2}=3.09, \mathrm{df}=1, p=\right.$ $.08)$ and significance at day $10\left(\chi^{2}=4.74, \mathrm{df}=1, p=.03\right)$.

From a low level of baseline symptom scores on the "Withdrawal Retardation" (5.3 \pm 4.0$)$ and "AnxietyDepression" ( $5.5 \pm 4.3)$ subscales of the BPRS in the entire group of neuroleptic-treated patients, no significant further improvement could be documented during the entire 28-day haloperidol trial $(F=1.37, \mathrm{df}=7,112, p=$ .23 and $F=1.18, \mathrm{df}=7,112, p=.32$, respectively). From a higher baseline "Paranoid Disturbance" BPRS subscale score $(8.4 \pm 4.0)$ there was a significant reduction in both lower- $(F=4.02, \mathrm{df}=7,56, p=.001)$ and high$(F=7.35, \mathrm{df}=7,49, p<.001)$ pHVA groups. However, the "Paranoid Disturbance" subscale score reductions from lower- and high-pHVA groups paralleled one another throughout the 28-day period of haloperidol treatment, demonstrating no significant difference between the two groups $(F=.266$, $\mathrm{df}=1,15, p=.966)$.

\section{Plasma Haloperidol in High- versus Lower-pHVA Groups on Days 7 and 14}

Plasma haloperidol levels did not differ between the two groups on day 7 (high-pHVA group [mean \pm SD] $=4.1 \pm$ $3.0 \mathrm{ng} / \mathrm{ml}$ versus lower-pHVA group $=4.7 \pm 2.4 \mathrm{ng} / \mathrm{ml}$ [Student's $t=.657, \mathrm{df}=15, p=.521$ ]) or on day 14 (high-pHVA group $=7.1 \pm 6.7 \mathrm{ng} / \mathrm{ml}$ versus lowerpHVA group $=7.7 \pm 2.6 \mathrm{ng} / \mathrm{ml}[$ Student's $t=.279, \mathrm{df}=$ $14, p=.785])$.

\section{Affective Features, Duration of Psychosis, and Response Patterns}

The premorbid pattern of episodes of better functioning and rapid antipsychotic response found in the highpHVA group could not be accounted for by the psychotic affective disorder subgroup of patients. The period of maximal social and vocational functioning in the past 5 years was $6.0 \pm 2.9$ in the psychotic affective disorders and $6.1 \pm 3.2$ in the nonaffective patients (Student's $t$-test: $t=.08, p=.93$ ). The antipsychotic response at day 7 of treatment was $25 \% \pm 7.1 \%$ in the psychotic affective disorders and $21.7 \% \pm 30.1 \%$ in the nonaffective disorder patients ( $t$-test: $t=.15, p=.88$ ). The rapidity of antipsychotic response was not related to the duration of psychosis, either from the first psychotic episode or from the onset of psychosis during the present psychotic episode. Thirteen of 17 psychotic patients treated with haloperidol had at least a $50 \%$ reduction of psychotic symptoms (BPRS " $\mathrm{S}$ ") before discharge. The length of time since the onset of the first psychotic episode and the duration of the present psychotic episode were not related to latency in days to such $50 \%$ improvement following initiation of haloperidol $\left(r_{p}=.17, p=.58\right.$, and $r_{p}=.49, p=.87$, respectively).

\section{Family Patterns of Illness}

Eight pedigrees consisting of 35 first-degree relatives of high-pHVA probands were available for study. A significant excess of schizophrenia was found in the pedigrees of high-pHVA probands compared to the general population. Three of $35(8.6 \%)$ of the first-degree relatives of the high-pHVA probands were diagnosed with DSM-III schizophrenia as contrasted to an expected 10 in 1,000 $(1 \%)$ in the general population $(z=3.18, p<.005)$. Familiality was also found in the lower-pHVA group. Five of $34(14.7 \%)$ of the first-degree relatives of the lowerpHVA probands were schizophrenic $(n=4)$ or schizotypal $(n=1)$ as contrasted to the general population $(z=$ $5.84, p<.005$ ). Because of the small sample and lack of power, no significant differences or trends were found between the pedigrees of high- and lower-pHVA patients.

\section{DISCUSSION}

The relevance of dopamine to psychosis, especially the occurrence of a hyper dopaminergic state in certain psychotic disorders, was proposed over 25 years ago (Van Rossum 1967). We provide at least indirect evidence for a discrete hyperdopaminergic psychotic disorder displaying a distinct, separable distribution of pHVA.

We first provided evidence that higher $\mathrm{PHVA}$, previously reported in some psychotics, is not distributed continuously in psychotic patients. We found a distinct bimodal pattern of pHVA distribution, suggestive of two separable patient populations. We confirmed that the upper mode of pHVA was not associated with elevated NE metabolism. We found that a more rapid antipsychotic response is associated with higher pHVA and that such rapid response (in comparison to a slower response in lower-pHVA psychotics) was not attributable to differences in plasma neuroleptic levels, in age of onset of psychosis, total duration of illness, or the age at index admission.

As expected, we found that presenting symptoms and DSM-III diagnostics poorly differentiated the highpHVA psychotics from other psychotic patients, but that high-pHVA psychotics had an illness course punctuated by repeated psychoses interspersed with periods of relatively good social and occupational functioning: an episodic psychosis. Response to antipsychotic drugs 
was more rapid and more complete in the high-pHVA psychotic patients. Finally, we presented evidence that the high-pHVA psychosis is a familial disorder, with higher risk for additional psychoses in the pedigree than the risk reported for the general population.

\section{Heterogeneity of Psychosis (the Schizophrenias)}

The bimodal distribution of pHVA levels, particularly in conjunction with differences in premorbid vocational and social adjustment and in the speed and degree of antipsychotic response, is highly suggestive of at least two groupings of diseases/conditions within the schizophrenic syndrome. Since the mid-1980s, much has been written about the heterogeneity of schizophrenia (Chang et al. 1990; Peralta et al. 1992; Chang et al. 1993), but there have been few systematic attempts to delineate one disease from others that rely on multiple converging biological or pharmacological domains. Bleuler's classic work, Dementia Praecox, or The Group of Schizophrenias (1911) implied such etiologic heterogeneity, but the tools for meaningful differentiation of one disease from another were not then available. Herein we present evidence compatible with the hypothesis that one of the diseases or conditions that make up the broader group of the schizophrenias (psychoses) may be the consequence of a failure of presynaptic dopamine control, resulting in a central hyperdopaminergic state associated with high pHVA.

\section{Psychotic Diseases or Disorders are NOT Delineated by Conventional Diagnostics or Symptomatic Presentations}

The high-pHVA or "dopamine psychosis" group cuts across conventional DSM-III diagnoses. High-pHVA was present in $35 \%$ of the schizophrenics, $50 \%$ of the schizophreniform disorders, and $64 \%$ of the psychotic affective disorders in our sample of 32 patients (Table 3). Symptom cluster subscales of the SADS failed to show symptomatic differences in the presentation of the "dopamine psychosis" as compared to the symptom clusters of other psychoses. Our finding of a trend toward a higher proportion of females with high pHVA has been reported by other investigators (Bowers et al. 1983; Bowers and Swigar 1987; Bowers 1991; Wei et al. 1992; Koreen et al. 1994).

\section{Skewing of Patient Samples toward a High-pHVA (Dopamine) Psychosis}

If it were not for selective admission policies that skewed the selection of psychotic patients to include subjects with a recent history of productive work and relatively good premorbid social adjustment, only a limited number of high-pHVA psychotics would have been studied. The availability of health insurance associated with productive employment of patients with a good prognosis functionally shunts a substantial portion of such better prognosis patients into private sector hospitals where they are rarely subjects of investigation. The consequent excess of psychotics with a poorer prognosis in public-sector hospitals (the location of most clinical research centers) and the reliance on DSM-III diagnoses (schizophrenia) for protocol entrance criteria typically result in a cohort of psychotic disorders that contain few psychotics with high pHVA.

\section{$\mathrm{D}_{2}$ Receptor Blockade and Antipsychotic Effects}

If psychosis is the consequence of the interaction of excess synaptic dopamine with $D_{2}$ receptors, effective $D_{2}$ blockade by conventional antipsychotic drugs would be expected to result in a very rapid elimination of hallucinations and thought disorder (Mazure et al. 1992), albeit a slower elimination of delusional gestalts. Bowers et al. (1984) have reported that such early responders $(\leq 10$ days) have higher $\mathrm{pHVA}$ than do other psychotic patients. We have previously reported a bimodal distribution of latency of antipsychotic response in a group of 42 moodincongruent psychotic patients that partially overlaps the present group of patients (Garver et al. 1988). Thirty-six percent of the cohort of psychotic patients had a $55 \%$ reduction of baseline psychosis scores by $5.0 \pm 2.0$ days after initiating antipsychotic treatment. The present study is, to our knowledge, the first to report a bimodal distribution of pHVA related to differences in the latency of response.

It has been suggested that the latency of antipsychotic response does not differ among psychotic patients, but that the early or rapid response seen in some psychotic patients is an artifact of a between-patient difference in the degree of response: patients who eventually respond to a greater degree than others simply show a steeper slope of response throughout the course of neuroleptic treatment, including the first few hours or days (Keck et al. 1989). Our present data do not document the ultimate outcome of a prolonged course of antipsychotic drug treatment (patients were generally discharged at their own request within a week following a $55 \%$ reduction of psychosis scores, and many could not be consistently followed during drug maintenance), but it is apparent that the slopes of change of psychotic symptoms are nearly identical after day 10 of neuroleptic treatment (Figure 2). The dramatic difference in slope of change of psychotic symptoms between the high- and lowerpHVA groups occurs in the first week of treatment; it is apparent by day 4 (Figure 2).

It has also been reported that in first-episode psychotics, the latency and completeness of neuroleptic-induced remission are positively correlated with the length of the psychotic episode prior to treatment (Loebel et al. 1992; Lieberman et al. 1993). This finding was not replicated by our data in patients a mean of $5.9 \pm 5.1$ years into 
their illness. Table 3 shows that the rapidly responding, high-pHVA psychotics have a (not significantly) longer total duration of psychotic illness than the delayedresponse, lower-pHVA group. The present data on duration of the present psychotic episode and duration of illness since first psychotic episode reveal no relationship with latency or completeness of response.

\section{Dopamine Excess versus Peripheral Adrenergic Excess in the "Dopamine Psychosis"}

As about $70 \%$ of pHVA does not come from the central nervous system, but is a byproduct of peripheral NE synthesis (Kopin et al. 1988; Amin et al. 1992), it is quite possible that elevated pHVA in a subgroup of psychotic patients is a byproduct associated with excess NE neuron activity. MHPG, the primary metabolite of NE found in plasma, is derived from both central and peripheral adrenergic activity. We found levels of pMHPG to be virtually identical in the high-pHVA and lower-pHVA psychotics, which implies that the elevated pHVA found in dopamine psychotics is not simply a consequence of excessive noradrenergic activity.

It is still possible that the bimodal distribution of pHVA in this group of psychotic patients is an artifact of a difference in the renal clearance of HVA. A modest variability in the renal clearance of HVA has been described in schizophrenic populations (Whelton et al. 1993). Treatment with antipsychotic drugs also has been found to alter renal clearance modestly (Karoum et al. 1987). Such clearance rates were not estimated in our study patients, and a remote possibility exists that the apparent pHVA differences documented are not due to the excessive production of dopamine, but to an impaired excretion of the metabolite. This possibility seems remote in view of other evidence concerning differences between the high- and lower-pHVA groups on the rate of antipsychotic response and the lack of difference in plasma haloperidol levels.

\section{Familial Nature of Both Dopamine Psychosis and Other Psychoses}

The pedigrees of dopamine psychosis probands (as well as other psychoses probands) were found to have significantly higher numbers of additional members with psychotic disorders than found in the general population. However, with the limited numbers of pedigrees of the high- and lower-pHVA probands studied, differences in the density or pattern of the psychoses in the pedigrees of the dopamine psychotics versus other psychotics could not be determined.

The data suggesting that dopamine psychosis is a disease separate from other forms of the psychoses would imply that the high-pHVA disease might be transmitted on a chromosomal site(s) whose location is unique from sites defining other, etiologically distinct forms of familial psychoses. It may be important in the next generation of linkage studies to segregate pedigrees by etiologically relevant markers (such as pHVA) to explore within-disease (rather than across-diseases) links (Garver et al. 1989).

\section{ACKNOWLEDGMENTS}

Supported in part by National Institutes of Mental Health, grant \#MH 42666 and VA Merit Review to DLG, Southwestern Medical Center, John Schermerhorn Psychiatric Fund.

\section{REFERENCES}

American Psychiatric Association, Committee of Nomenclature and Statistics (1980): Diagnostic and Statistical Manual of Mental Disorders, ed 3, Washington, DC, APA

Amin F, Davidson M, Davis KL (1992): Homovanillic acid measurement in clinical research: A review of methodology. Schizophr Bull 18:123-148

Anden NE, Butcher SG, Corrodi H, Fuxe K, Ungerstedt U (1970): Receptor activity and turnover of dopamine and noradrenaline after neuroleptics. Eur J Pharmacol 11:303-314

Anderson WH, Kuehnle JC, Catanzano DM (1976): Rapid treatment of acute psychosis. Am J Psychiatry 133:10761078

Angrist B, Gershon S (1977): Clinical response to several dopamine agonists in schizophrenic and nonschizophrenic subjects. Adv Biochem Psychopharmacol 16:677-680

Baker NJ, Stanton M, Adler LE, Gerhardt GA, Drebing C, Waldo M, Nagamoto H, Freedman R (1990): Sensory gating deficits in psychiatric inpatients: Relation to catecholamine metabolites in different diagnostic groups. Biol Psychiatry 27:519-528

Baldessarini RJ (1985): Antipsychotic agents. In Baldessarini RJ (ed), Chemotherapy in Psychiatry: Principles and Practice, ed 2, Cambridge, Harvard University Press, pp 14-92

Bianchetti G, Morselli PL (1978): Rapid and sensitive method for determination of haloperidol in human samples using nitrogen-phosphorus selective detection. J Chromatography 153:203-209

Bleuler E (1911): Dementia praecox, or the group of schizophrenias (trans. J Zinkin, 1950), New York, International Universities Press

Bowers MJ (1991): Characteristics of psychotic inpatients with high or low HVA levels at admission. Am J Psychiatry 148:240-243

Bowers MB Jr, Swigar ME (1987): Acute psychosis and plasma catecholamine metabolites. Arch Gen Psychiatry 44:190

Bowers MB, Swigar ME, Jatlow PI (1983): Sex differences in plasma homovanillic acid in acute psychosis. N Engl J Med 308:845-846

Bowers MB Jr, Swigar ME, Jatlow Pl, Goicoechea N (1984): 
Plasma catecholamine metabolites and early response to haloperidol. J Clin Psychiatry 45:248-251

Bowers MB Jr, Swigar ME, Jatlow PI, Hoffman F, Goicoechea $N$ (1986): Early neuroleptic response in psychotic men and women: Correlation with plasma HVA and MHPG. Comp Psychiatry 27:181-185

Chang WH, Scheinin M, Burns RS, Linnoila M (1983): Rapid and simple determination of homovanillic acid in plasma using high performance liquid chromatography with electrochemical detection. Acta Pharmacol Toxicol 53:275- 279

Chang WH, Chen TY, Lin SK, Lung FW, Lin WL, Hu WH, Yeh EK (1990): Plasma catecholamine metabolites in Schizophrenics: Evidence for the two-subtype concept. Biol Psychiatry 27:510-518

Chang WH, Hwu HG, Chen TY, Lin SK, Lung FW, Chen H, Lin WL, Hu WH, Lin HN, Chien CP (1993): Plasma homovanillic acid and treatment response in a large group of schizophrenic patients. Schizophr Res 10:259-265

Creese I, Burt DR, Snyder SH (1976): Dopamine receptor binding predicts clinical and pharmacological potencies of antischizophrenic drugs. Science 192:481-483

Davidson M, Davis KL (1988): A comparison of plasma homovanillic acid concentrations in schizophrenic patients and normal controls. Arch Gen Psychiatry 45:561-563

Donlon PT, Tupin J (1974): Rapid "digitalization" of decompensated schizophrenic patients with antipsychotic agents. Am J Psychiatry 131:310-312

Doran A, Pickar D, Labarca R, Douillet R, Wolkowitz O, Thomas J, Roy A, Dane S (1985): Evidence for a daily rhythm of plasma HVA in normal controls but not in schizophrenic patients. Psychopharmacol Bull 21:694-697

Endicott J (1978): SADS Summary Scale Scores, ed 3, New York, New York State Psychiatric Institute

Endicott J, Spitzer RL (1978): A diagnostic interview: The Schedule for Affective Disorders and Schizophrenia (SADS). Arch Gen Psychiatry 35:837-884

Garver DL, Kelly K, Fried KA, Magnusson M, Hirschowitz J (1988): Drug response patterns as a basis of nosology for the mood-congruent psychoses (the schizophrenias). Psychological Med 18:873-885

Garver DL, Reich T, Isenberg KE, Cloninger CR (1989): Schizophrenia and the question of genetic heterogeneity. Schizophr Bull 15:421-429

Glovinsky D, Kirch DG, Wyatt RJ (1992): Early antipsychotic response to resumption of neuroleptics in drug-free chronic schizophrenic patients. Biol Psychiatry 31:968-970

Hollister LE, Overall JE, Bennett JL, Kimbell I Jr, Shelton J (1967): Specific therapeutic actions of acetophenazine, perphenazine, and benzquinamide in newly admitted schizophrenic patients. Clin Pharmacol Therapeutics 8:249-255

Janowsky DS, Davis JM (1976): Methylphenidate, dextroamphetamine, and levamfetamine: Effects on schizophrenic symptoms. Arch Gen Psychiatry 33:304-308

Karoum F, Karson CN, Bigelow LB, Lawson WB, Wyatt RJ (1987): Preliminary evidence of reduced combined output of dopamine and its metabolites in chronic schizophrenia. Arch Gen Psychiatry 44:604-607
Keck PE, Cohen BM, Baldessarini RJ, McElroy SL (1989): Time course of antipsychotic effects of neuroleptic drugs. Am J Psychiatry 146:1289-1292

Kopin IF, Bankiewicz KS, Harvey-White J (1988): Assessment of brain dopamine metabolism from plasma HVA and MHPG during debrisoquin treatment: Validation in monkeys treated with MPTP. Neuropsychopharmacology 1:119-125

Koreen AR, Lieberman J, Alvir J, Mayerhoff D, Loebel A, Chakos M, Amin F, Cooper T (1994): Plasma homovanillic acid levels in first-episode schizophrenia: Psychopathology and treatment response. Arch Gen Psychiatry 51: 132-138

Lerner Y, Lwow E, Levitin A, Belmaker RH (1979): Acute high-dose parenteral haloperidol treatment of psychosis. Am J Psychiatry 136:1061-1064

Lieberman J, Jody D, Geisler S, Alvir J, Loebel A, Szymanski S, Woerner M, Borenstein M (1993): Time course and biologic correlates of treatment response in first-episode schizophrenia. Arch Gen Psychiatry 50:369-376

Loebel AD, Lieberman JA, Alvir JMJ, Mayerhoff DI, Geisler SH, Szymanski SR (1992): Duration of psychosis and outcome in first-episode schizophrenia. Am J Psychiatry 149:1183-1188

Markianos M, Botsis A, Arvanitis Y (1992): Biogenic amine metabolites in plasma of drug-naive schizophrenic patients: Associations with symptomatology. Biol Psychiatry 32:288-292

Mason AS, Granacher RP (1976): Basic principles of rapid neuroleptization. Dis Nerv Sys 37:547-551

Mazure CM, Nelson JC, Jatlow PI, Bowers MB Jr (1992): Drug-responsive symptoms during early neuroleptic treatment. Psychiatry Res 41:147-154

Neborsky R, Janowsky D, Munson E, Depry D, Schooler NR, Goldberg SC (1981): Rapid treatment of acute psychotic symptoms with high- and low-dose haloperidol. Arch Gen Psychiatry 38:195-199

Overall JE, Gorham DR (1962): The brief psychiatric rating scale. Psychological Reports 10:799-812

Peralta V, deLeon J, Cuesta MJ (1992): Are there more than two syndromes in schizophrenia? A critique of the positive-negative dichotomy. Brit J Psychiatry 161:335-343

Pickar D, Labarca R, Linnoila M, Roy A, Hommer D, Everett D, Paul SM (1984): Neuroleptic-induced decrease in plasma homovanillic acid and antipsychotic activity in schizophrenic patients. Science 225:954-957

Reschke RW (1973): Parenteral haloperidol for rapid control of severe, disruptive symptoms of acute schizophrenia. Dis Nerv Sys 35:112-115

Reynolds GP (1983): Increased concentrations and lateral asymmetry of amydgala dopamine in schizophrenia. Nature 305:527-529

Sautter F, Hitzemann R, Griffin J, Garver DL (1986): Lithium ratio in vitro: Familial patterns of illness. Psychiatry Res $18: 257-266$

Scheinin M, Chang WH, Kirk KL, Linnoila M (1983): Simultaneous determination of 3-methoxy-4-hydroxyphenylglycol, 5-hydroxyindoleacetic acid, and homovanillic acid 
in cerebrospinal fluid with high-performance liquid chromatography using electrochemical detection. Analyt Biochem 131:246-253

Seeman P, Chau-Wong M, Tedesco J, Wong K (1975): Brain receptors for antipsychotic drugs and dopamine: Direct binding assays. Proc Nat Acad Sci U S A 72:4376-4380

Seeman P, Ulpian C, Bergeron C, Riederer P, Jellinger K, Gabriel E, Reynolds GP, Tourtellotte WW (1984): Bimodal distribution of dopamine receptor densities in brains of schizophrenics. Science 225(4663):728-731

Seeman P, Guan H, Van Tol HHM (1993): Dopamine $D_{4}$ receptors elevated in schizophrenia. Nature 365:441-445

SigmaStat for Windows (1992-1994): User's Manual, San Rafael, Ca, Jandel Scientific

Snyder SH, Kuhar MJ, Gjedde A (1986): Positron emission tomography reveals elevated $D_{2}$ dopamine receptors in drug naive schizophrenics. Science 234:1558-1563

Steinberg JL, Garver DL, Moeller FG, Raese JD, Orsulak PJ (1993): Serum homovanillic acid levels in schizophrenic patients and normal control subjects. Psychiatry Res 48:93-106

Stone CK, Garver DL, Griffith J, Hirschowitz J, Bennett J (1995): Further evidence of a dose-response threshold for haloperidol in psychosis. Am J Psychiatry 152:1210-1212

SYSTAT for Windows (1992): Getting Started, Version 5 Edition, Evanston, IL, SYSTAT, Inc.

Van Kammen DP, Bunney WE Jr, Docherty JP, Marder SR,
Ebert MH, Rosenblatt JE, Rayner JN (1982): d-amphetamine-induced heterogeneous changes in psychotic behavior in schizophrenia. Am J Psychiatry 139:991-997

Van Putten T, Marder SR, Aravagiri M, Chabert N, Mintz J (1989): Plasma homovanillic acid as a predictor of response to fluphenazine treatment. Psychological Bull 1:89-91

Van Rossum JM (1967): The significance of dopamine-receptor blockade for the action of neuroleptic drugs. In Brill $\mathrm{H}$, Cole J, Deniker P, Hippius H, Bradley PB (eds), Proceedings of the Fifth Collegium Internationale Neuropsychopharmacologicum, Amsterdam, Excerpta Medica Foundation, pp 321-329

Wei J, Ramchand CN, Hemmings GP (1992): Studies on concentrations of NA and HVA and activity of DBH in the serum from schizophrenic patients, first-degree relatives and normal subjects. Schizophr Res 8:103-110

Whelton CL, Gupta RN, Cleghorn JM, Ballagh SR (1993): Influence of renal clearance on peripheral homovanillic acid measurements in healthy subjects and schizophrenic patients. Schizophr Res 11:33-40

Winer BJ, Brown DR, Michels KM (1991): Statistical Principles in Experimental Design, New York, McGraw-Hill, Inc.

Wong DF, Wagner HN Jr, Tune LE, Dannals RF, Pearlson GD, Links JM, Tamminga CA, Broussole EP, Ravert HT, Wilson AA, Thomas Toung JK, Malat J, Williams JA, O'Tuama LA, Snyder SH, Kuhar MJ, Gjedde A (1986): Positron emission tomography reveals elevated $D_{2}$ dopamine receptors in drug-naive schizophrenics. Science 234:1558-1563 